\title{
Mannose regulates water balance, leaf senescence, and genes related to stress tolerance in white clover under osmotic stress
}

\author{
S.Y. ZHAO, W.H. ZENG, Z. LI*, and Y. PENG \\ Department of Grassland Science, College of Animal Science and Technology, \\ Sichuan Agricultural University, Chengdu 61130, P.R. China
}

\begin{abstract}
Mannose (MAN), an important monosaccharide, contributes to coping with abiotic stresses in plants. Objectives of this study were to examine whether exogenous MAN $(30 \mathrm{mM})$ could significantly increase drought tolerance and further to reveal MAN-regulated tolerance mechanism in white clover under osmotic stress induced by $18 \%$ (m/v) polyethylene glycol 6000 for $10 \mathrm{~d}$ in controlled growth chambers. Results show that the application of MAN significanlty alleviated stress damage and the inhibition of growth and photosynthesis in white clover under osmotic stress. The MAN-induced increase in endogenous MAN content and the accumulation of organic osmolytes (proline and water soluble sugars) could be responsible for a lower osmotic potential (OP) in white clover. The exogenous application of MAN also enhanced antioxidant enzyme (superoxide dismutase, peroxidase, ascorbate peroxidase, dehydroascorbate reductase, and glutathione reductase) activities and maintained ascorbic acid content in white clover during osmotic stress. As concern chlorophyll (Chl) metabolism, the MAN-treated plants showed significantly higher transcription of genes involved in Chl synthesis Mg-chelatase and protochlorophyllide reductase and lower transcription of pheophorbide a oxygenase and chlorophyllase related to $\mathrm{Chl}$ degradation and also a senescence associated gene 101 than untreated plants. In addition, the MAN application increased transcription of SK2-, Y2K-, and Y2SK-type dehydrin genes, and dehydrin b in leaves of white clover under osmotic stress. These results indicate that MAN plays important roles in drought tolerance not only acting as a compatible solute for OP but also delaying leaf senescence through enhancing antioxidant metabolism, decreasing Chl degradation, and increasing transcription of dehydrin genes contributing to enhanced drought tolerance in white clover.
\end{abstract}

Additional key words: antioxidants, dehydrins, osmotic potential, photosynthesis, senescence, Trifolium repens.

\section{Introduction}

Plants are often exposed to different environmental stresses under natural conditions. Drought has become one of the most critical factors limiting plant growth and development due to global warming and persistent decrease in available irrigation water worldwide (Zlatev and Lidon 2012). For the improvement of stress resistance in plants, the application of plant growth regulators (PGRs) has many advantages such as simple operation, quick effect, and high practical value. For example, the PGR application on ornamental plants can increase their stress resistance (Chu et al. 2004). Indolebutyric acid (IBA) and gibberellic acid (GA) can alleviate negative effects of water deficit on photosynthesis and dry matter accumulation in cotton (Zhao and Oosterhuis 1997, Biles and Cothren 2001). Exogenous $\gamma$-aminobutyric acid (GABA) could significantly improve heat and drought tolerance in creeping bentgrass associated with the alteration of transcriptions of stressprotective genes including transcription factors and genes encoding antioxidant enzymes, heat shock proteins, and metallothionein (Li et al. 2018). Previous studies have also

Submitted 2 December 2019, last revision 28 January 2020, accepted 29 January 2020.

Abbreviations: APX - ascorbate peroxidase; ASA - ascorbic acid; C - control conditions; CAT - catalase; Chl - chlorophyll; CHLASE - chlorophyllase; DHAR - dehydroascorbate reductase; EL - electrolyte leakage; $F_{v} / F_{m}$ - variable to maximum fluorescence ratio (maximum quantum yield of photosystem II photochemical efficiency); GR - glutathione reductase; GSH - glutathione; MAN - mannose; MDA - malondialdehyde; MDHAR - monodehydroascorbate reductase; Mg-CHT - Mg-chelatase; OP - osmotic potential; PGRs - plant growth regulators; PIABS - performance index on absorption basis; $\mathrm{P}_{\mathrm{N}}$ - net photosynthetic rate; POD - peroxidase; PAO - pheophorbide a oxygenase; PBGD - porphobilinogen deaminase; POR - protochlorophyllide reductase; Pro - proline; RGR - relative growth rate; ROS - reactive oxygen species; RWC - relative water content; SAG101 - senescence-associated gene 101; SK2 - SK2-type dehydrin; SOD - superoxide dismutase; TAC - total antioxidant capacity; WSS - water soluble saccharides; WUE - water use efficiency; Y2K - Y2K-type dehydrin; Y2SK - Y2SK-type dehydrin.

Acknowledgments: This research was supported by the Sichuan Science and Technology Program (Grant No. 2017HH0060) and the National Natural Science Foundation of China (Grant No. 31702182). The first two authors contributed equally to this work.

* Corresponding author; e-mail: lizhou1986814@163.com 
shown that application of abscisic acid (ABA), salicylic acid (SA), and jasmonic acid (JA) could improve the drought tolerance in various plant species (Ali et al. 2017, Li et al. 2017a), but the price of these PGRs is relatively high. In addition, the application effects and advantages of different PGRs vary with plant species.

Mannose (MAN), an important monosaccharide, contributes to tolerance to abiotic stresses as a compatible solute in plants. For example, exogenous GABA, ABA, and SA could significantly enhance the MAN accumulation associated with increases in osmotic adjustment (OA) and drought tolerance in creeping bentgrass ( $\mathrm{Li}$ et al. 2017a). Under drought, MAN priming could effectively increrase biochemical processes in wheat seeds, thereby increasing drought tolerance during seeds germination (Hameed and Iqbal 2014). The transgenic Arabidopsis plants overexpressing a gene encoding Medicago sativa GDP-mannose-3',5'-epimerase effectively enhanced acid, drought, and salt tolerance associated with the regulation of ascorbate accumulation (Ma et al. 2014). The overexpression of a tomato GMP (a gene related to GDPmannose biosynthesis) improved antioxidant capacity leading to the enhancement of heat and cold tolerance in tobacco (Wang et al. 2011). These studies confirm that MAN not only acts as an important osmolyte, but also plays other multiple roles in regulating abiotic stress tolerance in plants. In addition, the MAN is characterized by low price, non-toxic side effects, and low concentration regulation as compared to other PGRs. The further investigation into MAN function in growth regulation and stress tolerance has high practical and scientific value.

White clover (Trifolium repens) is one of the most important leguminous forage worldwide due to strong biological nitrogen fixation function and high nutrient value. In addition, white clover is also applied to ornamental turf because of its better creeping growth characteristics, fast regeneration speed, and graceful leaf shape (Zhao et al. 2004). However, white clover is a cool-season and shallow-root plant and prefers cold and moist climate. Drought has become the main limiting factor for its production and utilization, especially in the subtropical and temperate regions (Frame and Newbould 1986). Objectives of this study was to investigate whether exogenous MAN could significantly enhance drought tolerance of white clover and further to reveal the MANregulated mechanism possibly involved in osmotic protection, antioxidant and chlorophyll metabolism, leaf senescence, and expression of dehydrin-encoded genes in white clover under control and osmotic stress conditions.

\section{Materials and methods}

Plants and treatments: White clover (Trifolium repens L.) drought-tolerant cv. Haifa was used and seeds were purchased from Barenbrug, Beijing, China. Seeds were uniformly sprinkled in the seedling-raising plate $(15 \mathrm{~cm}$ length, $15 \mathrm{~cm}$ width, and $20 \mathrm{~cm}$ height) filled with moistened quartz sands in controlled growth chamber set at day/night temperatures of $23 / 19^{\circ} \mathrm{C}$, an irradiance of $750 \mu \mathrm{mol} \mathrm{m} \mathrm{m}^{-2} \mathrm{~s}^{-1}$ (photosynthetically active radiation, PAR), and a relative humidity of $70 \%$. After $7 \mathrm{~d}$ of seed germination, seedlings of white clover were watered by Hoagland's solution (Hoagland and Arnon 1950) and after $30 \mathrm{~d}$, they were treated by $30 \mathrm{mM}$ MAN for $3 \mathrm{~d}$. Then MAN-treated or untreated plants were carefully removed from quartz sands and subjected to PEG-induced osmotic stress. The concentration of MAN was chosen based on a preliminary test with a range of concentrations $(0,10,20$, 30,40 , and $50 \mathrm{mM}$ ) for the most effective concentration on phenotypic changes. Four treatments were set: 1) controls were grown in Hoagland's solution $(\mathrm{C}) ; 2$ ) plants were pretreated by Hoagland's solution containing 30 mM MAN for $3 \mathrm{~d}$ and then grown in standard Hoagland's solution $(\mathrm{C}+\mathrm{MAN})$; 3) plants were grown in Hoagland's solution containing $18 \%$ PEG 6000 (m/v) (PEG); and 4) plants were pretreated by Hoagland's solution containing $30 \mathrm{mM}$ MAN for $3 \mathrm{~d}$ and then grown in Hoagland's solution containing $18 \%$ PEG 6000 (PEG+MAN). The Hoagland's and $\mathrm{PEG}$ solutions were refreshed every day to avoid the change in concentration and aerated by pumps (115 V, $60 \mathrm{~Hz}$, Tetra ${ }^{\circledR}$, Blacksburg, VA, USA). Leaves were sampled at $0,4,6,8$, and $10 \mathrm{~d}$ of control cultivation or osmotic stress. Each treatment had four independent biological replicates.

Relative growth rate (RGR) was determined by using the formula: RGR $\left[\mathrm{mg} \mathrm{g}^{-1}(\mathrm{~d} . \mathrm{m}.) \mathrm{d}^{-1}\right]=(\operatorname{lnMf}-\operatorname{lnMi}) / \Delta \mathrm{t}$, where Mi is initial and Mf final dry masses (d.m.) of plants and $\Delta t$ means the elapsed time between two measurements (Ma et al. 2012).

For electrolyte leakage (EL) determination, fresh leaves $(0.1 \mathrm{~g})$ were immersed in $20 \mathrm{~cm}^{3}$ of deionized water at $4{ }^{\circ} \mathrm{C}$ for $24 \mathrm{~h}$. The initial conductivity $\left(\mathrm{C}_{\text {initial }}\right)$ was detected by using a conductivity meter (DDS-307A, Shanghai Precision and. Scientific Instrument, Shanghai, China). Leaves were autoclaved in an oven at $105{ }^{\circ} \mathrm{C}$ for $90 \mathrm{~min}$ and the maximum conductivity $\left(\mathrm{C}_{\max }\right)$ was measured. $\mathrm{EL}[\%]=\mathrm{C}_{\text {initial }} / \mathrm{C}_{\max } \times 100$ (Blum and Ebercon 1981).

Leaf relative water content (RWC) was determined as: RWC $[\%]=[(\mathrm{FM}-\mathrm{DM}) /(\mathrm{WSM}-\mathrm{DM})] \times 100$, where FM, $\mathrm{DM}$, and WSM are fresh, dry, and water saturated masses, respectively. Leaves were collected from plants and FM immediately measured. Then they were wrapped in gauze and kept in distilled water at $4{ }^{\circ} \mathrm{C}$ for $12 \mathrm{~h}$ for determining WSM. After that, leaves were dried in an oven for $72 \mathrm{~h}$ and weighed for DM (Barrs and Weatherley 1962).

Osmotic potential (OP) was determined according to the method of Blum (1989). Fresh leaves were collected and immersed in deionized water at $4{ }^{\circ} \mathrm{C}$ for $8 \mathrm{~h}$. Leaves were blotted dry and pressed. Osmolarity (c) of cell fluid was measured using an osmometer (Wescor, Logan, UT, USA); $\mathrm{OP}[\mathrm{MPa}]=-\mathrm{c} \times 2.58 \times 10^{-3}$.

Water soluble saccharides (WSS) were detected based on the method of Buysse and Merckx (1993) with some modification. The $20 \mathrm{mg}$ of dry leaf powder was mixed 
with $10 \mathrm{~cm}^{3}$ of $80 \%(\mathrm{v} / \mathrm{v})$ ethanol and then extracted in boiling water bath for $15 \mathrm{~min}$. Extract was then centrifuged at $3600 \mathrm{~g}$ for $10 \mathrm{~min}$ to get the supernatant. Absorbance was read at $625 \mathrm{~nm}$ using a spectrophotometer (Spectronic 601, Spectronic Instruments, Rochester, NY, USA).

For determination of free proline (Pro), fresh leaves $(0.1 \mathrm{~g})$ were immersed in $5 \mathrm{~cm}^{3}$ of $3 \%(\mathrm{~m} / \mathrm{v})$ aqueous sulfosalicylic acid for $1 \mathrm{~h}$ at room temperature. Homogenate was centrifuged at $3000 \mathrm{~g}$ for $10 \mathrm{~min}$ and $2 \mathrm{~cm}^{3}$ of supernatant was mixed with $2 \mathrm{~cm}^{3}$ of glacial acetic acid and $2 \mathrm{~cm}^{3}$ of acid ninhydrin solution and then the mixture was heated in a water bath $\left(100^{\circ} \mathrm{C}\right)$ for $1 \mathrm{~h}$ and cooled in ice water. Then $5 \mathrm{~cm}^{3}$ of toluene was added. Absorbance was read at $520 \mathrm{~nm}$ using a spectrophotometer (Bates et al. 1973).

Content of MAN in leaves was determined by using mannose assay kits (Suzhou Comin Biotechnology Company, Suzhou, China).

Antioxidants: Fresh leaves $(0.1 \mathrm{~g})$ were ground with cold phosphate buffer $\left(4 \mathrm{~cm}^{3}, 50 \mathrm{mM}, \mathrm{pH} \mathrm{7.6}\right)$. The homogenate was centrifuged at $12000 \mathrm{~g}$ and $4{ }^{\circ} \mathrm{C}$ for $30 \mathrm{~min}$. The supernatant was used for assays of antioxidant enzyme activities and malondialdehyde (MDA) content. Superoxide dismutase (SOD) activity was measured by recording the rate of $p$-nitroblue tetrazolium chloride reduction according to changes in absorbance at $560 \mathrm{~nm}$ (Giannopolitis and Ries 1977). The activities of catalase (CAT), peroxidase (POD), ascorbate peroxidase (APX), monodehydroascorbate reductase (MDHAR), dehydroascorbate reductase (DHAR), and glutathione reductase (GR) were determined by following the changes in absorbance at 240, 470, 290, 340, 265, and $340 \mathrm{~nm}$, respectively (Nakano and Asada 1981). For each enzyme and total antioxidant capacities, a unit (U) means the amount of enzyme catalyzing reaction of $1 \mu \mathrm{mol}$ of a substrate in $1 \mathrm{~min}$. Protein content was determined according to Bradford (1976). For the determination of MDA content, enzyme extract $\left(0.5 \mathrm{~cm}^{3}\right)$ was mixed with reaction solution $\left(1 \mathrm{~cm}^{3}\right)$ containing $20 \%(\mathrm{~m} / \mathrm{v})$ trichloroacetic acid and $0.5 \%(\mathrm{~m} / \mathrm{v})$ thiobarbituric acid. The mixture was heated in a water bath at $95{ }^{\circ} \mathrm{C}$ for $15 \mathrm{~min}$ and cooled quickly in ice water. The homogenate was centrifuged at $8000 \mathrm{~g}$ for $10 \mathrm{~min}$. The absorbance of supernatant was measured at 532,600, and $450 \mathrm{~nm}$ (Li et al. 2015b). The formation rate of $\mathrm{O}_{2}^{-}$was measured by using sulfanilamide and the absorbance was measured at $530 \mathrm{~nm}$ (Elstner and Heupel 1976). Content of $\mathrm{H}_{2} \mathrm{O}_{2}$ was assayed by potassium iodide method (Velikova et al. 2000). Total antioxidant capacity (TAC), ascorbic acid (ASA), and glutathione (GSH) content were determined by using assay kits purchased from Suzhou Comin Biotechnology Company.

Determination of photosynthetic characteristics: For determination of chlorophyll $(\mathrm{Chl})$ content, fresh leaves $(0.1 \mathrm{~g})$ were immersed in $10 \mathrm{~cm}^{3}$ of $80 \%(\mathrm{v} / \mathrm{v})$ acetone and $95 \%(\mathrm{v} / \mathrm{v})$ alcohol mixture $(1: 1, \mathrm{v} / \mathrm{v})$ and left in the dark for $48 \mathrm{~h}$. The extract was measured at 663 and $645 \mathrm{~nm}$ with a spectrophotometer. Content of Chl was calculated using the formula described in Arnon (1949). Maximum quantum yield of photosystem II photochemical efficiency $\left(\mathrm{F}_{\mathrm{v}} / \mathrm{F}_{\mathrm{m}}\right)$ and performance index on absorption basis (PIABS) were measured by using a chlorophyll fluorescence meter (Pocket PEA, Hansatech, Norfolk, UK). Individual leaves were adapted to darkness for $30 \mathrm{~min}$ using leaf clips. $\mathrm{F}_{\mathrm{v}} / \mathrm{F}_{\mathrm{m}}$ ratio and PIABS were recorded. Net photosynthetic rate $\left(\mathrm{P}_{\mathrm{N}}\right)$ and water use efficiency (WUE) were determined by using a portable photosynthesis system (CIRAS-3, PP Systems, Amesbury, MA, USA). This instrument provided a $\mathrm{CO}_{2}$ concentration of $400 \mathrm{~mm}^{3} \mathrm{dm}^{-3}$ and an red and blue irradiation of $800 \mu \mathrm{mol}$ (photon) $\mathrm{m}^{-2} \mathrm{~s}^{-1}$.

Gene transcriptions were performed using real-time quantitative qPCR (Table 1 Suppl.). For total RNA, fresh leaves $(0.1 \mathrm{~g})$ were extracted by using RNeasy Mini kit (Qiagen, Düsseldorf, Germany). An RNA was reversetranscribed to cDNA using a Revert Aid First Stand cDNA synthesis kit (Fermentas, Vilnius, Lithuania). The cDNA was subjected to quantitative PCR using primers of genes involved in $\mathrm{Chl}$ synthesis and degradation $(\mathrm{Mg}$ chelatase - Mg-CHT, protochlorophyllide reductase POR, porphobilinogen deaminase - PBGD, pheophorbide a oxygenase - PAO, chlorophyllase - CHLASE), a senescence marker gene (senescence-associated gene 101 - SAG101), and dehydrin-encoded genes (SK2-, Y2K-, and $Y 2 S K$-type dehydrins - SK2, Y2K, and Y2SK). $\beta$-Actin was used as internal control. Conditions of PCR protocol for all genes were as follows: at $94{ }^{\circ} \mathrm{C}$ for $5 \mathrm{~min}$, at $95{ }^{\circ} \mathrm{C}$ for $30 \mathrm{~s}$ (40 repeats), at $56-60{ }^{\circ} \mathrm{C}$ for $45 \mathrm{~s}$. The formula $2^{-\Delta \Delta \mathrm{Ct}}$ was used to calculate the transcription of all genes at the end of PCR cycle (Xia et al. 2009).

Statistical analysis: The data was analyzed by one-way ANOVA using SPSS 20 (IBM, Armonk, NY, USA). The significant differences among treatments were tested based on the least significant difference (LSD) at $P \leq 0.05$.

\section{Results}

Exogenous MAN (30 mM) did not significantly affect RGR, RWC, and EL in white clover under control conditions (Fig. 1A-D). The osmotic stress significantly decreased RGR and RWC in leaves of white clover treated with or without MAN relative to control conditions (Fig. $B, C$ ). Exogenous MAN significantly improved RGR under osmotic stress (Fig. $1 B$ ); MAN-treated white clover had a significantly higher leaf RWC than untreated plants at 8 and $10 \mathrm{~d}$ of osmotic stress (Fig. 1C). Osmotic stress caused a significant increase in EL in both MAN-treated and untreated plants (PEG+MAN and PEG), but the PEG+MAN had lower EL than PEG at 6, 8, and $10 \mathrm{~d}$ of osmotic stress (Fig. 1D). OP and WSS, MAN, and free Pro content in leaves are not significantly affected by MAN treatment under control conditions (Fig. 2). PEG application significantly decreased OP in both MANtreated and untreated plants and the MAN-treated white clovers had lower OP than untreated plants (Fig. 2A). 


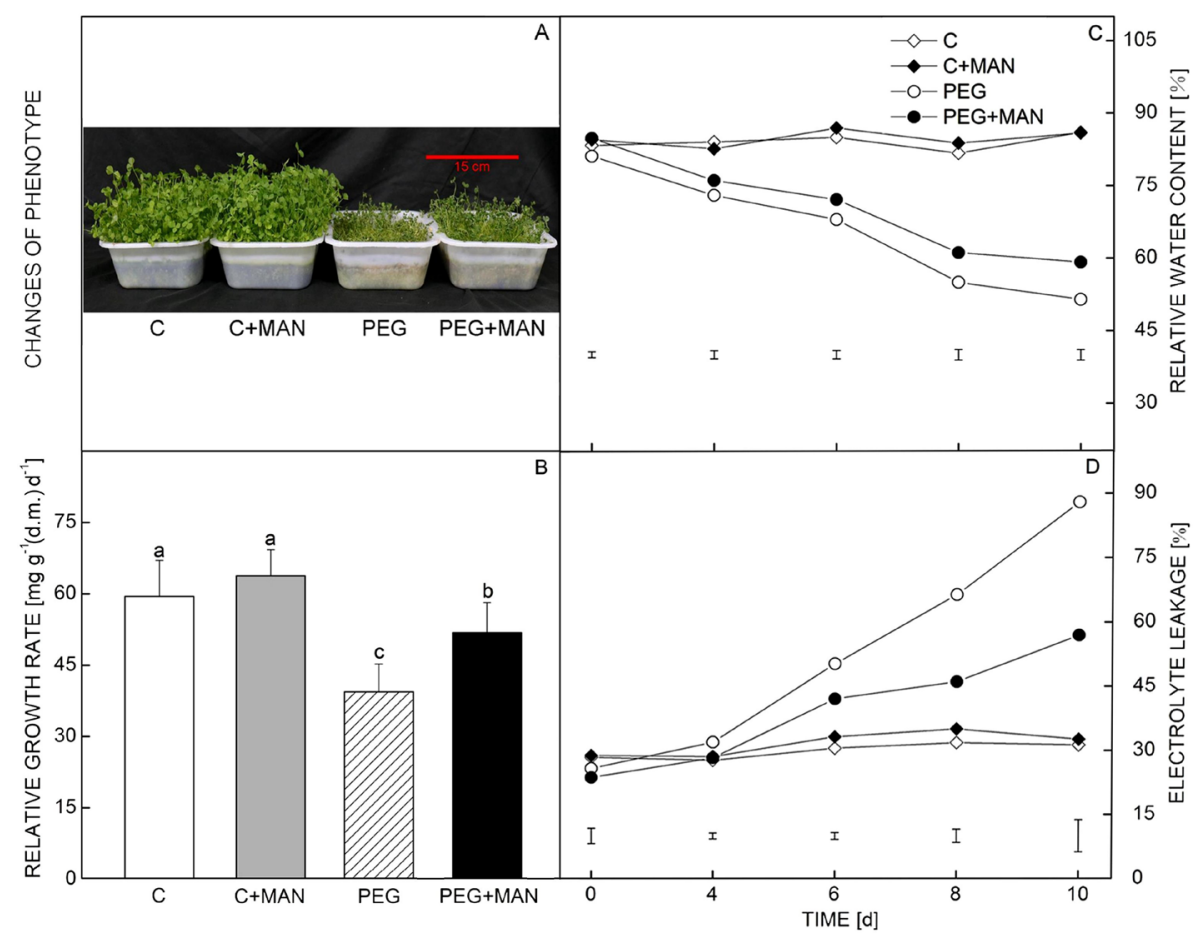

Fig. 1. Effects of mannose (MAN) on the phenotypic response $(A)$, relative growth rate $(B)$, relative water content $(C)$, and electrolyte leakage $(D)$ in leaves of white clover under control and osmotic stress conditions. Treatments: control (C), mannose under control conditions (C+MAN); polyethylene glycol-induced osmotic stress (PEG), PEG-induced osmotic stress in plants treated with MAN (PEG+MAN). Means \pm SEs, $n=4$; different letters indicate significant differences among treatments based on the least significant difference (LSD) at $P \leq 0.05$. Vertical bars below curves represent LSD values at a given day of treatment.

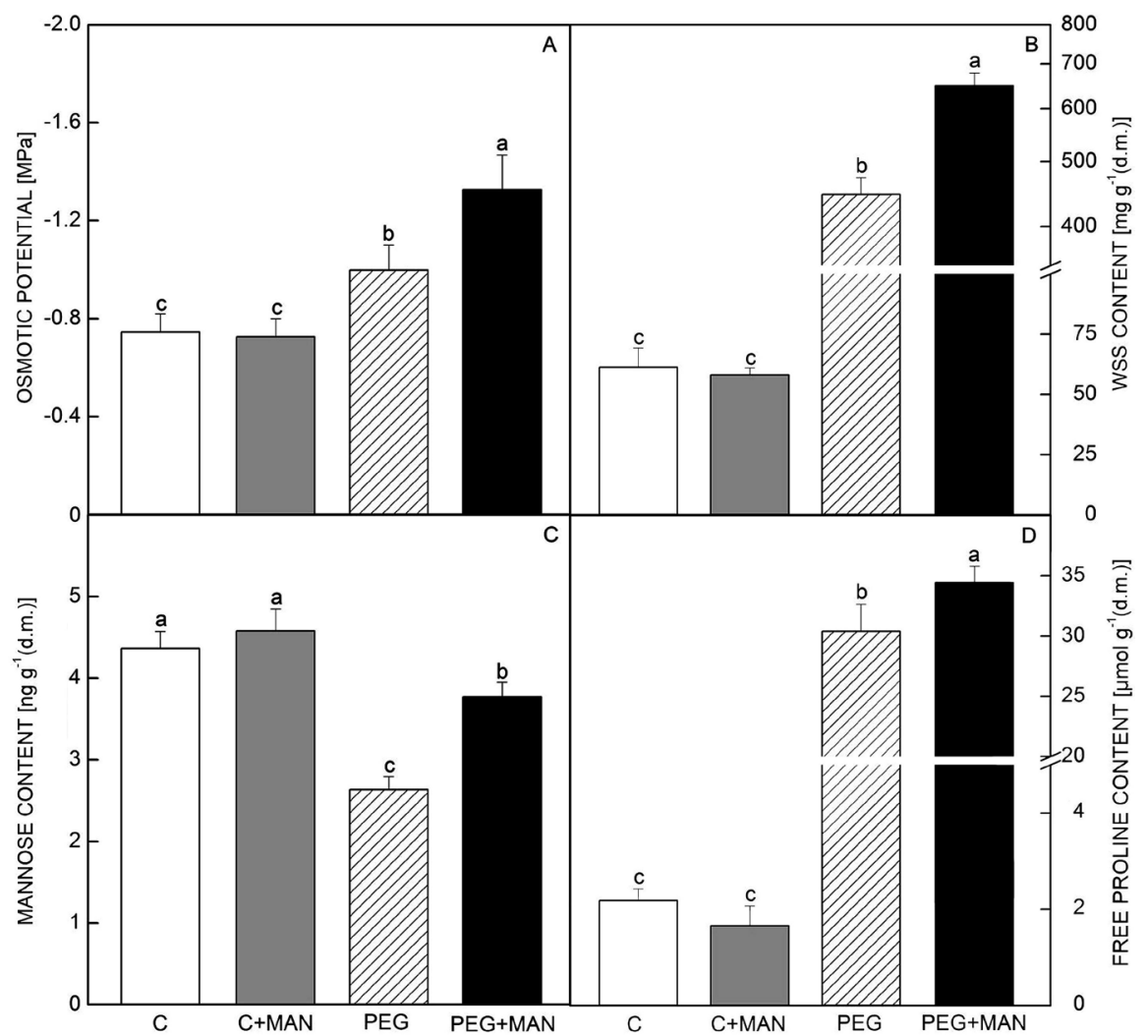

Fig. 2. Effects of mannose (MAN) on osmotic potntial $(A)$, water soluble saccharides, WSS $(B)$, mannose content $(C)$, and free proline content $(D)$ in leaves of white clover under control and osmotic stress conditions. For other abbreviations, see Fig. 1 . Means \pm SEs, $n=$ 4; different letters indicate significant differences among treatments based on the least significant difference at $P \leq 0.05$. 
The MAN-treated white clovers exhibited 45, 43, and $1.33 \%$ increases in WSS, MAN, and free Pro content than untreated plants under PEG tretment (Fig. 2B-D).

Osmotic stress induced by PEG caused significant increases in $\mathrm{O}_{2}^{-}, \mathrm{H}_{2} \mathrm{O}_{2}, \mathrm{MDA}$, and TAC in leaves as compared to well-watered control (Fig. 3) but these parameters were not significantly affected by MAN treatment under control conditions. Under osmotic stress, the MAN-treated white clover had 42, 21, and $24 \%$ lower $\mathrm{O}_{2}^{-}, \mathrm{H}_{2} \mathrm{O}_{2}$, and MDA content, respectively, than untreated plants (Fig. $3 A-C$ ) and TAC in leaves of MANtreated white clover was $82 \%$ higher than that in leaves of white clover without MAN treatment under osmotic stress (Fig. 3D). The activities of SOD, CAT, POD, APX, DHAR, GR, and MDHAR, and ASA and GSH content are not significantly affected by exogenous MAN under control conditions (Fig. 4). Application of MAN also had no effects on CAT activity, MDHAR activity, and GSH content under osmotic stress (Fig. 4B, G,I). The MANtreated white clover exhibited $14,17,44,22$, and $32 \%$ higher SOD, POD, APX, and GR activities and ASA content, respectively, than untreated plants under osmotic stress (Fig. 4A,C,D,F,H). DHAR activity in leaves of plants treated with MAN was twice higher than that those treated only by PEG (Fig. 4E).

The application of MAN did not significantly affect $\mathrm{F}_{\mathrm{v}} / \mathrm{F}_{\mathrm{m}}$, PIABS, $\mathrm{P}_{\mathrm{N}}$, and WUE in leaves during $10 \mathrm{~d}$ under control conditions (Fig. 5). Osmotic stress significantly decreased $F_{v} / F_{m}$, PIABS, and $P_{N}$ in leaves of MAN-treated and untreated white clovers at 8 and $10 \mathrm{~d}$ of osmotic stress, but MAN-treated plants exhibited significantly higher $\mathrm{F}_{\mathrm{v}} / \mathrm{F}_{\mathrm{m}}$, PIABS, and $\mathrm{P}_{\mathrm{N}}$ than untreated plants under osmotic stress (Fig. 5A-C). MAN-treated plants had twice and seven times higher PIABS than untreated plants at 8 and $10 \mathrm{~d}$ of osmotic stress, respectively (Fig. $5 B$ ). The MANtreated plants also exhibited 32 and $51 \%$ increases in WUE than untreated plants at 8 and $10 \mathrm{~d}$ of PEG-induced stress, respectively (Fig. 5D).

Chlorophyll content and transcriptions of five different genes ( $M g-C H T, P O R, P B G D, P A O$, and CHLASE) taking part in Chl synthesis and degradation were not affected significantly by MAN treatment under control conditions, but exogenous MAN caused a significant increase in $P B G D$ transcription under control conditions (Fig. 6). The MANtreated leaves exhibited $48 \%$ increase in $\mathrm{Chl}$ content than untreated leaves under osmotic stress (Fig. 4J). Under osmotic stress, MAN-treated plants had 33 and $47 \%$ higher $\mathrm{Mg}-\mathrm{CHT}$ and $\mathrm{POR}$ transcriptions than untreated plants (Fig. 6B,C). Exogenous MAN had no significant effect on the transcription of $P B G D$ in leaves under osmotic stress (Fig. 6D). However, application of MAN significantly inhibited stress-induced $P A O$ and CHLASE expressions (Fig. 6E,F). Osmotic stress significantly enhanced the senescence marker gene $S A G 101$ transcription in both of MAN-treated and untreated white clovers (Fig. 6A), but the $S A G 101$ transcription in leaves of MAN-treated

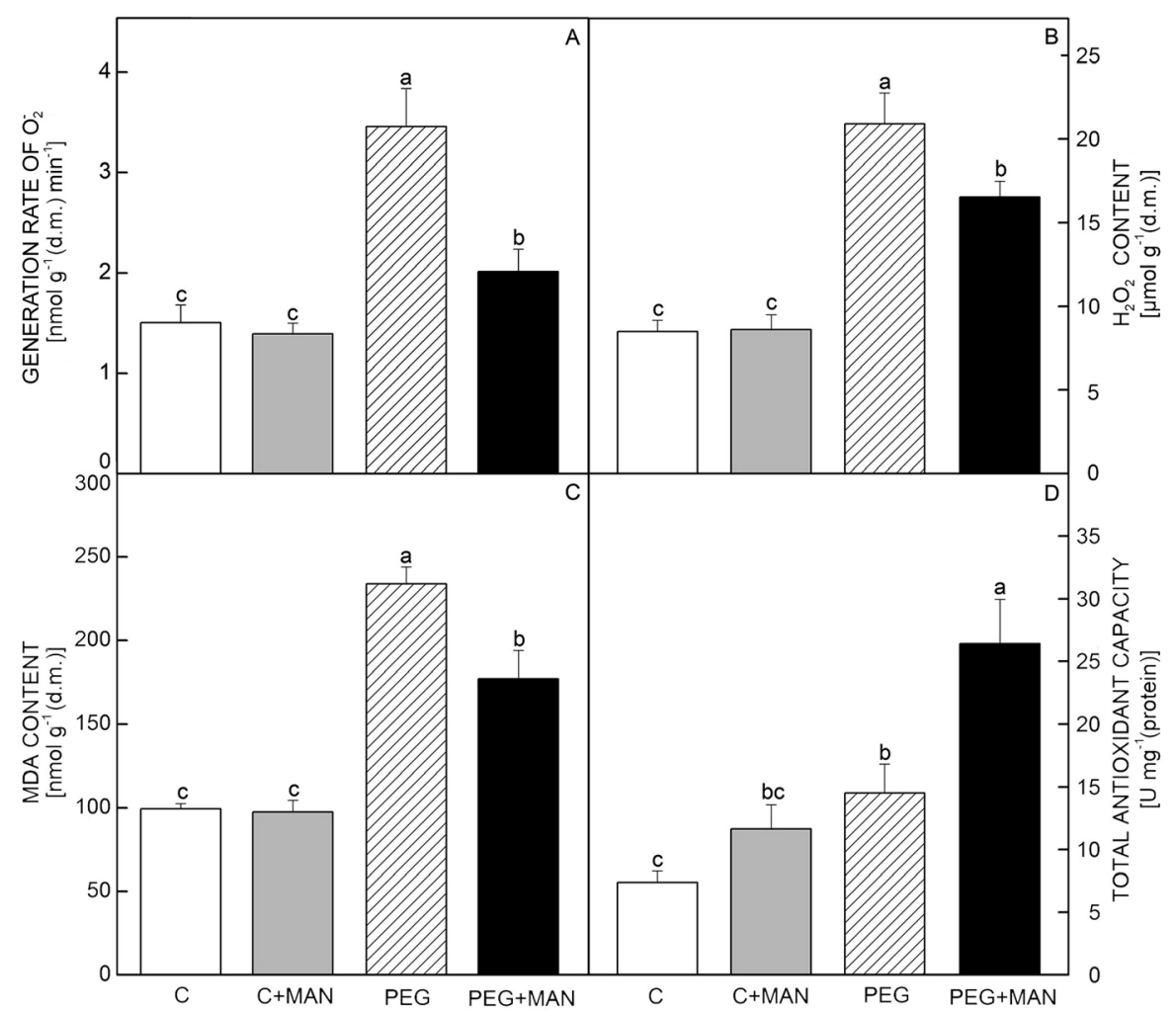

Fig. 3. Effects of mannose (MAN) on superoxide anion $\left(\mathrm{O}_{2}^{-}\right)$generation $(A), \mathrm{H}_{2} \mathrm{O}_{2}$ content $(B)$, malondialdehyde (MDA) content $(C)$, and total antioxidant capacity $(D)$ in leaves of white clover under control and osmotic stress conditions. For other abbreviations, see Fig. 1. Means \pm SEs, $n=4$; different letters indicate significant differences among treatments based on the least significant difference at $P \leq 0.05$. 
plants was significantly lower than in those without MAN treatment under osmotic stress (Fig. 6A).

Transcriptions of four genes $(S K 2, Y 2 K, Y 2 S K$, and dehydrin $b$ ) encoding different dehydrins were examined in this study. Osmotic stress singificantly up-regulated expressions of these genes (Fig. 7). Although

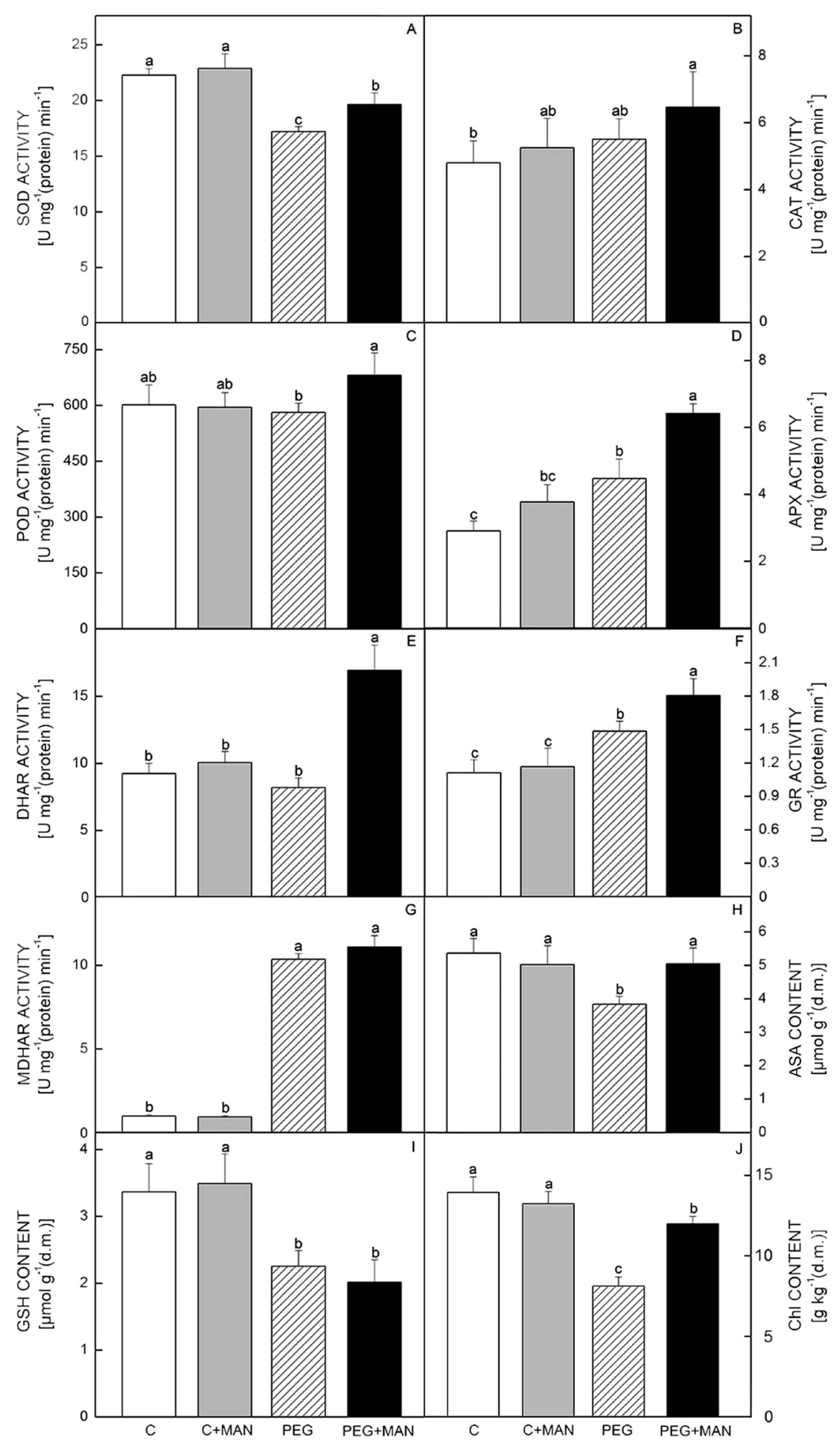

Fig. 4. Effects of mannose (MAN) on superoxide dismutase (SOD) activity $(A)$, catalase (CAT) activity (B), peroxidase (POD) activity $(C)$, ascorbate peroxidase (APX) activity $(D)$, dehydroascorbate reductase (DHAR) activity $(E)$, glutathione reductase (GR) activity $(F)$, monodehydroascorbate reductase (MDHAR) activity $(G)$, ascorbic acid (ASA) content $(H)$, glutathione (GSH) content $(I)$, and chlorophyll (CHL) content $(J)$ in leaves of white clover under control and osmotic stress conditions. For other abbreviations, see Fig. 1. Means \pm SEs, $n=4$; different letters indicate significant differences among treatments based on the least significant difference at $P \leq 0.05$. 
exogenous MAN did not cause significant effects on their transcriptions under control conditions, the application of MAN significantly enhanced their transcriptions under osmotic stress. Transcription of SK2 in leaves of MANtreated white clover was twice as high as that in leaves without MAN treatment under osmotic stress. The 59, 73 , and $45 \%$ increases in $Y 2 K, Y 2 S K$ and dehydrin $b$ transcriptions were observed in MAN-treated white clovers as compared to that in untreated plants under osmotic stress, respectively (Fig. 7).

\section{Discussion}

Osmotic stress usually results in wilting and growth inhibition. To alleviate plant damage, the osmotic adjustment is necessary to mainten water absorption, and the osmoprotection to maintain structure and function of plant cells under decreased water content (Hasegawa et al. 2000, Lambers et al. 2006). Our data showed that the increase in endogenous MAN content induced by MAN application caused significant increases in WSS and free pro accumulation in leaves of white clover under osmotic stress. It is well-known that sugars contributes to osmotic adjustment in response to water deficit and also they are sources of available energy for plant growth (Di Fonzo et al. 2000). Previous studies have shown that the accumulation of souble sugars in wheat contributed to better drought tolerance (Hakimi et al. 1995, Kamaljit et al. 2007). The application of spermine (Spm) significantly increased accumulation of sucrose and fructose in two white clover cultivars, thereby alleviating droughtinduced water deficit (Li et al. 2015a). Proline exhibits positive function in osmotic adjustment, osmoprotection, and the detoxification of reactive oxygen species (ROS) in various plant species; and plant cells can accumulate a large amount of proline without detrimental side effects (Yancey et al. 1982, Ashraf and Foolad 2007, Kocsy et al. 2005). Proline is also an important source of nitrogen or energy in plants (Verslues and Sharp 1999). In this study, exogenous MAN-induced increases in MAN, WSS, and free pro content help to decrease OP and so better water absorption and also provide more available energy for growth of white clover under osmotic stress.

A long period of osmotic stress disturbs the balance of ROS metabolism leading to severe oxidative damage in plants. Both enzymatic and non-enzymatic antioxidants are involved in alleviating oxidative damage in plant tissue (Soares et al. 2016). The SOD catalyzes transformation of $\mathrm{O}_{2}{ }^{-}$into $\mathrm{H}_{2} \mathrm{O}_{2}$, which is the first step of ROS scavenging (Mckersie et al. 1993). Other antioxidant enzymes such as APX, POD, and CAT are responsible for transformation of $\mathrm{H}_{2} \mathrm{O}_{2}$ into $\mathrm{H}_{2} \mathrm{O}$ and $\mathrm{O}_{2}$ (Farooq et al. 2009). Previous studies have proved that higher antioxidant enzyme activities are directly related to higher protections and better stress tolerance in different plant species under drought stress (Bermejo et al. 2006, Hameed et al. 2013). Hameed et al. (2009) found that MAN could modulate activities of POD and APX which contribute to detoxifying ROS in wheat leaves. For non-enzymatic antioxidants, ASA-GSH cycle is mainly responsible for scavenging $\mathrm{H}_{2} \mathrm{O}_{2}$ in different cellular compartments (Asada 1992, Ai et al. 2016). The accumulation of ASA and GSH or enhanced ASA-GSH cycle can improve drought tolerance in white clover or other plant species (Eltayeb et al.2006, Hasanuzzaman and Fujita 2011, Li et al. 2016). In our study, exogenous MAN significantly promoted SOD, POD, APX, DHAR, and GR activities, maintained significantly higher ASA

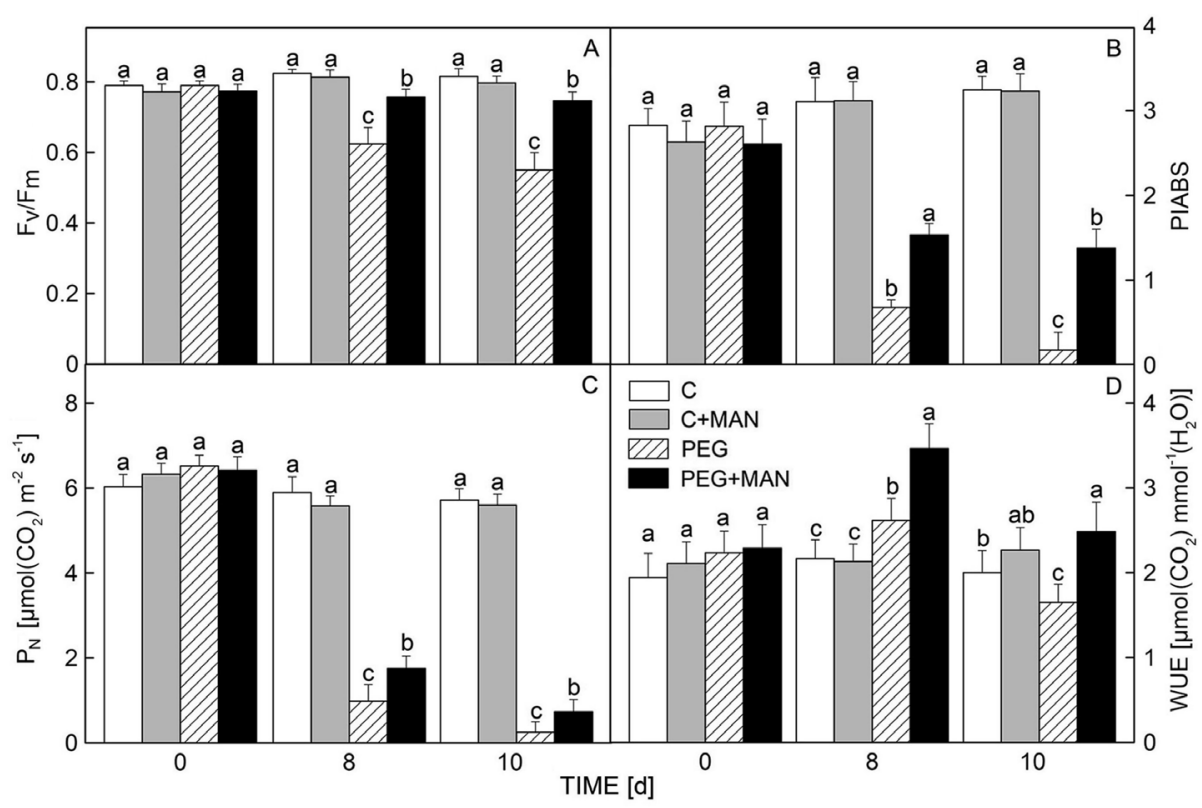

Fig. 5. Effects of mannose (MAN) on photochemical efficiency $\left(\mathrm{F}_{\mathrm{v}} / \mathrm{F}_{\mathrm{m}}\right)(A)$, performance index on absorption basis (PIABS) (B), net photosynthetic rate, $\mathrm{P}_{\mathrm{N}}(C)$, and water use efficiency (WUE) $(D)$ in leaves of white clover under control and osmotic stress conditions. For other abbreviations see Fig. 1. Means \pm SEs, $n=4$; different letters indicate significant differences among treatments based on the least significant difference at $P \leq 0.05$. 
content and also TAC, thereby inhibiting $\mathrm{O}_{2}^{-}, \mathrm{H}_{2} \mathrm{O}_{2}$, and MDA accumulation in leaves of white clover under osmotic stress. This data indicate that exogenous MAN improves the tolerance to osmotic stress associated with the enhancement of antioxidant defense and effective alleviation of oxidative damage in white clover.

Under abiotic stress, the overaccumulation of ROS damages cell membrane and photosynthetic organs leading to $\mathrm{Chl}$ degradation and senescence in plants (Rosenvasser et al. 2006). PAO and CHLASE are two main enzymes involved in $\mathrm{Chl}$ degradation in plants. It has been proved that drought- or heat-induced Chl loss was closely related to the up-regulation of $P A O$ and CHLASE expression in grass species (Jespersen et al. 2016, Li et al. 2017b, Zhang et al. 2016). The inhibition of Chl degradation could obviously suppress leaf senescence of perennial ryegrass (Zhang et al. 2015). Our current study showed that MAN pretreatment could significantly down-regulate stressinduced increases in transcriptions of $P A O$ and CHLASE in leaves of white clover. Interestingly, MAN-treated white clover also could maintain significantly higher transcriptions of $\mathrm{Mg}-\mathrm{CHT}$ and $\mathrm{POR}$ in response to osmotic stress. PBGD, Mg-CHT, and POR are three major enzymes regulating chlorophyll synthesis. PBGD can combine four porphobilinogen subunits to generate a porphyrin ring, $\mathrm{Mg}-\mathrm{CHT}$ is responsible for inserting a magnesium ion into the porphyrin ring, and POR controls the final step in chlorophyll synthesis to generate chlorophyllide (Bollivar 2006). Our previous study has found that suitable concentration of $\mathrm{Na}^{+}(30 \mathrm{mM})$ pretreatment

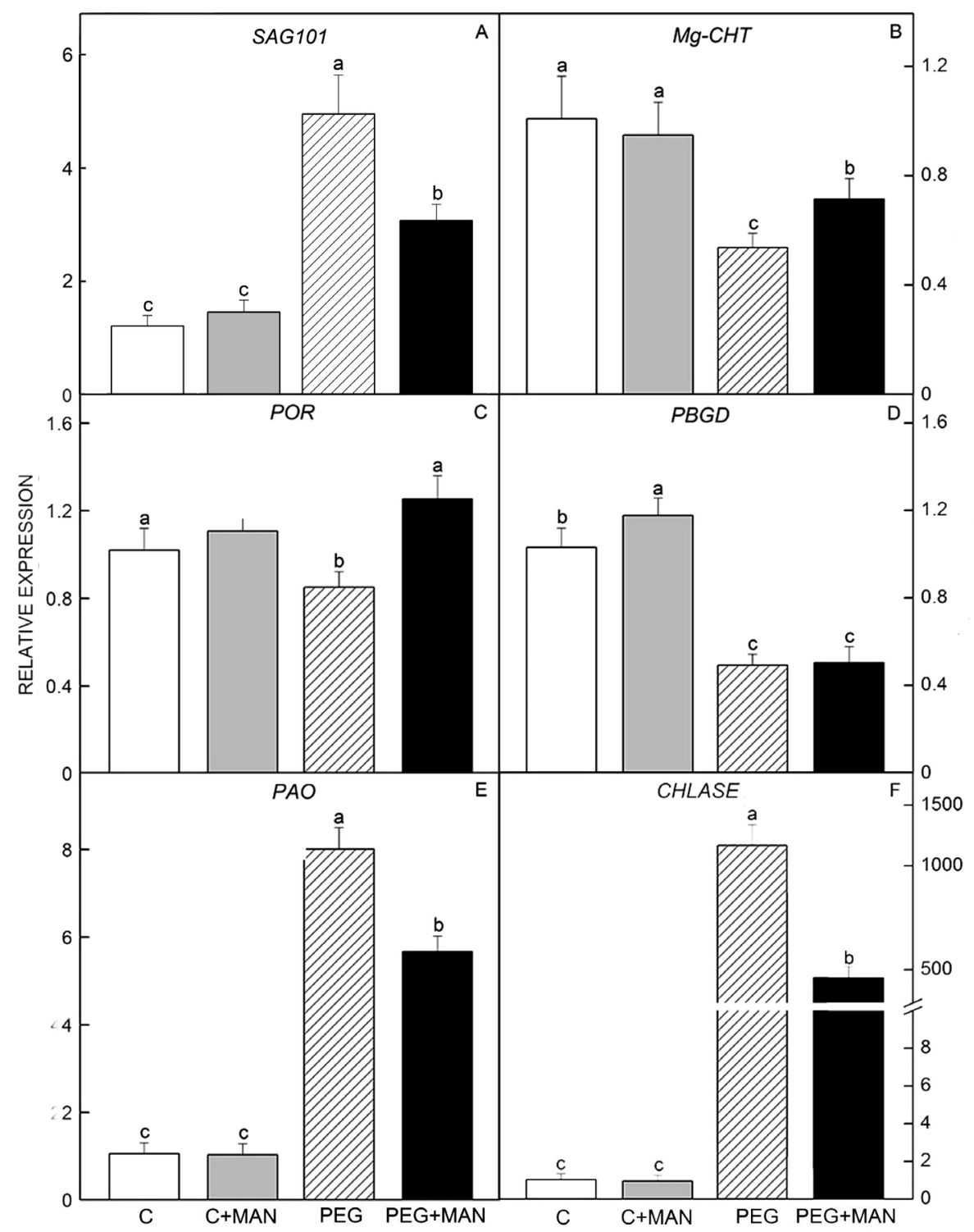

Fig. 6. Effects of mannose (MAN) on senescence-associated gene 101 (SAG101) relative expression (A), Mg-chelatase (Mg-CHT) relative expression $(B)$, protochlorophyllide reductase $(P O R)$ relative expression $(C)$, porphobilinogen deaminase $(P B G D)$ relative expression $(D)$, pheophorbide a oxygenase $(P A O)$ relative expression $(E)$, and chlorophyllase (CHLASE) relative expression $(F)$ in leaves of white clover under control and osmotic stress conditions. For other abbreviations see Fig. 1 . Means \pm SEs, $n=4$; different letters indicate significant differences among treatments based on the least significant difference at $P \leq 0.05$. 
could significantly up-regulated $P O R$ and $\mathrm{Mg}-\mathrm{CHT}$, but inhibited drought-induced $P A O$ expression, which effectively decreased $\mathrm{Chl}$ degradation and suppressed leaf senescence in white clover (Li et al. 2017b). In this study, the application of MAN maintained Chl synthesis and inhibited $\mathrm{Chl}$ degradation, which contributed to delaying leaf senescence and maintaining higher photosynthetic performance in white clover under osmotic stress.

In higher plants, the increase in dehydrin accumulation is another key adaptive mechanism in response to various abiotic stresses including drought or osmotic stress. Dehydrins have multiple positive function such as cell membrane and structures protection, osmotic adjustment, prevention of cell dehydration, and antioxidant activity when plants respond to harsh environment (Bian et al. 2002, Heyen et al. 2002, Hanin et al. 2011). It was reported that the drought-tolerant white clover had higher transcriptions of dehydrin genes than sensitive cultivar under osmotic stress (Vaseva et al. 2011). Transcriptions of genes encoding dehydrins in Dendrobium candidum contributed to dehydration and freezing tolerance (Bian et al. 2002). The study of Li et al. (2015a) also found that exogenous Spm could significantly alleviate PEG-induced osmotic stress damage in white clover through enhancing dehydrin accumulation and dehydrin-encoded genes expression. Our current findings showed that osmotic stress caused significant increases in transcriptions of dehydrin genes $(S K 2, Y 2 K, Y 2 S K$, and dehydrinb), which were important adaptive responses to osmotic stress. Interestingly, the MAN application could further enhance transcriptions of $S K 2, Y 2 K$ and $Y 2 S K$ and dehydrinb in leaves of white clover under osmotic stress. Thus, MANregulated tolerance to osmotic stress in white clover is closely related to expressions of dehydrin genes.

\section{Conclusions}

Applications of suitable dose of MAN could significantly improve tolerance to osmotic stress in white clover. Physiological analyses showed that exogenous MAN induced significant increase in endogenous MAN, proline, and WSS content contributing to lower OP and better water balance in white clover. The application of MAN also activated antioxidant enzymes (SOD, POD, APX, DHAR, and GR) and maintained enhanced ASA content in white clover under osmotic stress, thereby effectively alleviating oxidative damage. In response to osmotic stress, the MAN-treated white clover could maintain significantly higher photosynthesis and transcription of genes involved in Chl synthesis ( $\mathrm{Mg}$ - $\mathrm{CHT}$ and POR) and decrease stressinduced transcription of $P A O$ and $C H L A S E$ genes relating to Chl degradation as well as the senescence marker gene SAG101. In addition, the MAN application further improved transcriptions of genes encoding dehydrins (SK2, Y2K, Y2SK, and dehydrinb) in leaves of white clover

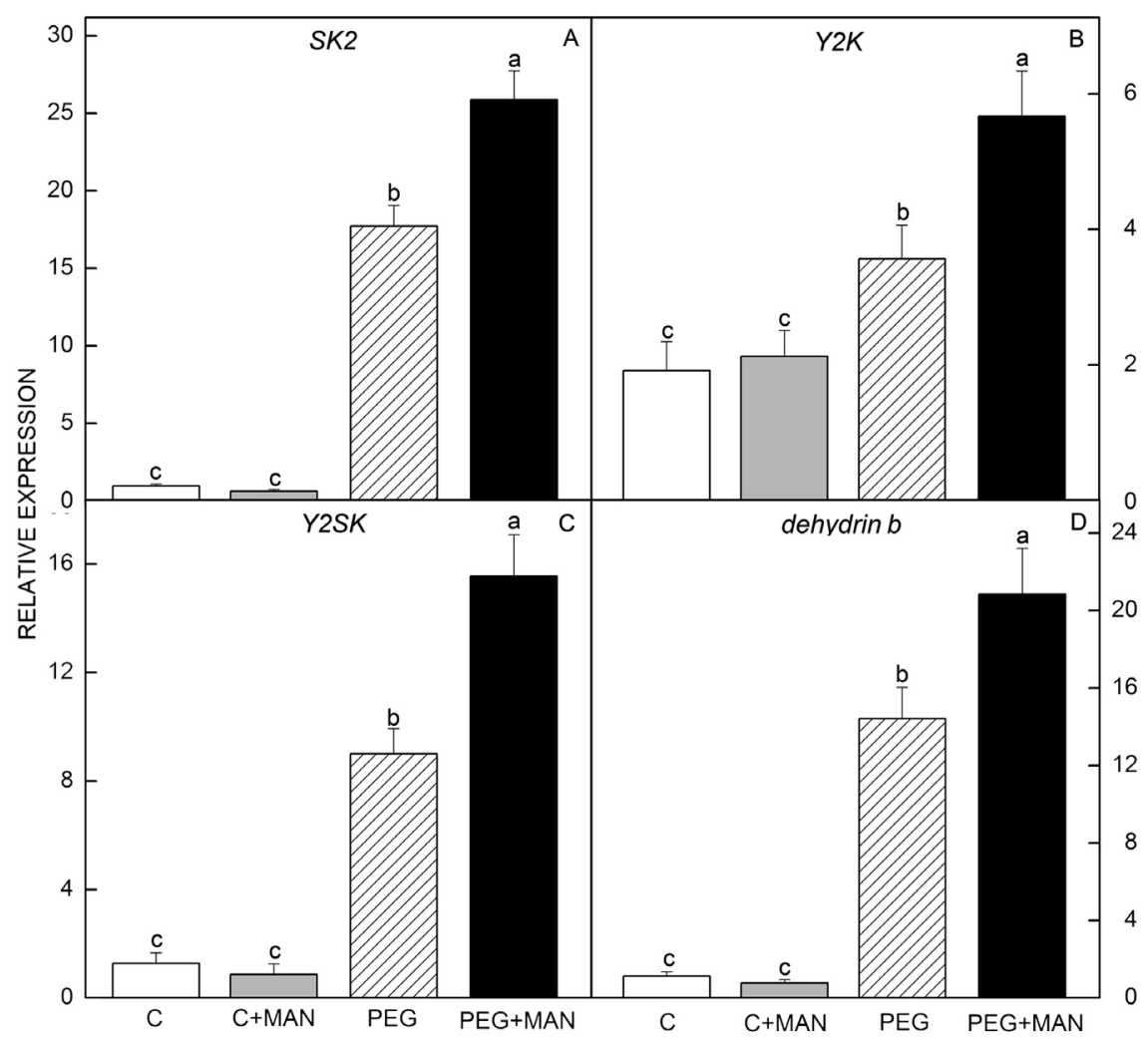

Fig. 7. Effects of mannose (MAN) on SK2-type dehydrin (SK2) relative expression $(A), Y 2 K$-type dehydrin $(Y 2 K)$ relative expression $(B), Y 2 S K$-type dehydrin $(Y 2 S K)$ relative expression $(C)$, and dehydrin $b$ relative expression $(D)$ in leaves of white clover under control and osmotic stress conditions. For other abbreviations, see Fig. 1. Means \pm SEs, $n=4$; different letters indicate significant differences among treatments based on the least significant difference at $P \leq 0.05$. 
under osmotic stress. These results indicate that MAN not only acts as an important compatible solute for OP, but also delays leaf senescence through enhancing antioxidant metabolism, decreasing Chl degradation, and increasing transcriptions of dehydrin genes contributing to enhanced drought tolerance in white clover. Current results provide new evidence for better understanding beneficial function of MAN when plants suffer from harsh environmental conditions.

\section{References}

Ai, T., Liao, X., Li, R., Fan, L., Luo, F., Xu, Y., Wang, S.: GDP-Dmannose pyrophosphorylase from Pogonatherum paniceum enhances salinity and drought tolerance of transgenic tobacco. - Z. Naturforsch. C. 71: 243-252, 2016.

Ali, F., Bano, A., Fazal, A.: Recent methods of drought stress tolerance in plants. - Plant Growth Regul. 82: 1-13, 2017.

Arnon, D.I.: Copper enzymes in isolated chloroplasts. Polyphenoloxidase in Beta vulgaris. - Plant Physiol. 24: 1-15, 1949.

Asada, K.: Ascorbate peroxidase - a hydrogen peroxidescavenging enzyme in plants. - Physiol. Plant. 85: 235-241, 1992.

Ashraf, M., Foolad, M.R.: Roles of glycine betaine and proline in improving plant abiotic stress resistance. - Environ. exp. Bot. 59: 206-216, 2007.

Barrs, H,D., Weatherley, P.E.: A re-examination of the relative turgidity technique for estimating water deficits in leaves. Aust. J. biol. Sci. 15: 413-428, 1962.

Bates, L.S., Waldren, R.P., Teare, I.D.: Rapid determination of free proline for water-stress studies. - Plant Soil. 39: 205-207, 1973.

Bermejo, R., Irigoyen, J.J., Santamaria, J.M.: Short-term drought response of two white clover clones, sensitive and tolerant to $\mathrm{O}_{3}$. - Physiol. Plant. 127: 658-669, 2006.

Bian, H.W., Wang, J.H., Lin, W.Q., Han, N., Zhu, M.Y.: Accumulation of soluble sugars, heat-stable proteins and dehydrins in cryopreservation of protocorm-like bodies of Dendrobium candidum by the air-drying method. - Plant Physiol. 159: 1139-1145, 2002

Biles, S.P., Cothren, J.T.: Flowering and yield response of cotton to application of mepiquat chloride and PGR-IV. - Crop Sci. 41: 1834-1837, 2001.

Blum, A.: Osmotic adjustment and growth of barley genotypes under drought stress. - Crop Sci. 29: 230-233, 1989.

Blum, A., Ebercon, A.: Cell membrane stability as a measure of drought and heat tolerance in wheat. - Crop Sci. 21: 43-47, 1981.

Bollivar, D.W.: Recent advances in chlorophyll biosynthesis. Photosynth. Res. 90: 173-194, 2006.

Bradford, M.M.: A rapid and sensitive method for the quantitation of microgram quantities of protein utilizing the principle of protein-dye binding. - Anal. Biochem. 72: 248-254, 1976.

Buysse, J., Merckx, R.: An improved colorimetric method to quantify sugar content of plant tissue. - Environ. exp. Bot. 44: 1627-1629, 1993.

Chu, A.X., Kong, X.S., Zhang, Y.Z.: Application of plant growth regulator on ornamental plant. - Acta hort. sin. 31: 408-412, 2004.

Di Fonzo, N., Campanile, R.G., Stoppelli, M.C., Spano, G., Rascio, A., Russo, M., Trono, D., Padalino, L., Laus, M., De Vita, P., Troccoli, A., Flagella, Z., Shewry, P.R., Lawlor, D.: Resistance to abiotic stresses in durum wheat: which ideotype? - In: Royo, C. Nachit, M., Di Fonzo, N., Araus, J.L. (ed.): Durum Wheat Improvement in the Mediterranean Region: New Challenges. Pp. 215-225. CIHEAM, Zaragoza 2000.

Elstner, E.F., Heupel, A.: Inhibition of nitrite formation from hydroxylammoniumchloride: a simple assay for superoxide dismutase. - Anal. Biochem. 70: 616-620, 1976.

Eltayeb, A.E., Kawano, N., Badawi, G., Kaminaka, H., Sanekata, T., Morishima, I., Shibahara, T., Inanaga, S., Tanaka, K.: Enhanced tolerance to ozone and drought stresses in transgenic tobacco overexpressing dehydroascorbate reductase in cytosol. - Plant Cell Physiol. 127: 57-65, 2006.

Farooq, M., Wahid, A., Kobayashi, N., Fujita, D., Basra, S.M.A.: Plant drought stress: effects, mechanisms and management. Agron. Sustain. Dev. 29: 185-212, 2009.

Frame, J., Newbould, P.: Agronomy of white clover. - Adv. Agron. 40: 1-88, 1986.

Giannopolitis, C.N., Ries, S.K.: Superoxide dismutases: I. occurrence in higher plants. - Plant Physiol. 59: 309-314, 1977.

Hakimi, A.A., Monneveux, P., Galiba, G.: Soluble sugars, proline and relative water content (RWC) as traits for improving drought tolerance and divergent selection for RWC from $T$. polonicum into T. durum. - J. Genet. Plant Breed. 49: 237243, 1995.

Hameed,A., Iqbal, N., Malik, S.A.: Mannose-induced modulations in antioxidants, protease activity, lipid peroxidation, and total phenolics in etiolated wheat leaves. - J. Plant Growth Regul. 28: 58-65, 2009.

Hameed, A., Iqbal, N.: Chemo-priming with mannose, mannitol and $\mathrm{H}_{2} \mathrm{O}_{2}$ mitigate drought stress in wheat. - Cereal. Res. Commun. 42: 450-462, 2014.

Hameed, A., Goher, M., Iqbal, N.: Drought induced programmed cell death and associated changes in antioxidants, proteases and lipid peroxidation in wheat leaves. - Biol. Plant. 57: 370374, 2013.

Hanin, M., Brini, F., Ebel, C., Toda, Y., Takeda, S., Masmoudi, K.: Plant dehydrins and stress tolerance: versatile proteins for complex mechanisms. - Plant Signal. Behav. 6: 1503-1509, 2011.

Hasanuzzaman, M., Fujita, M.: Selenium pretreatment upregulates the antioxidant defense and methylglyoxal detoxification system and confers enhanced tolerance to drought stress in rapeseed seedlings. - Biol. Trace Elements Res. 143: 1758-1776, 2011.

Hasegawa, P.M., Bressan, R.A., Zhu, J.K., Bohnert, H.J.: Plant cellular and molecular responses ro high salinity. - Annu. Rev. Plant Physiol. Plant mol. Biol. 51: 463-499, 2000.

Heyen, B.J., Alsheikh, M.K., Smith, E.A., Torvik, C.F., Seals, D.F., Randall, S.K.: The calcium-binding activity of a vacuole-associated, dehydrin-like protein is regulated by phosphorylation. - Plant Physiol. 130: 675-687, 2002.

Hoagland, D.R., Arnon, D.I.: The water-culture method for growing plants without soil. - Calif. Agr. Exp. Sta. Circ. 347: 357-359. 1950.

Jespersen, D., Zhang, J., Huang, B.: Chlorophyll loss associated with heat-induced senescence in bentgrass. - Plant Sci. 249: 1-12, 2016.

Kamaljit, K., Gupta, A.K., Narinder, K.: Effect of water deficit on carbohydrate status and enzymes of carbohydrate metabolism in seedlings of wheat cultivars. - Indian J. Biochem. Biophys. 44: 223-230, 2007.

Kocsy, G., Laurie, R., Szila, G., Szilagyi, V., Simon-Sarkadi, L., Galiba, G., De Ronde, J.A.: Genetic manipulation of proline levels affects antioxidants in soybean subjected to simultaneous drought and heat stresses. - Physiol. Plant. 124: 
$227-235,2005$

Lambers, H., Shane, M.W., Cramer, M.D., Pearse, S.J., Veneklaas, E.J.: Root structure and functioning for efficient acquisition of phosphorus: matching morphological and physiological traits. - Ann. Bot. 98: 693-713, 2006.

Li, Z., Jing, W., Peng, Y., Zhang, X., Ma, X., Huang, L., Yan, Y.: Spermine alleviates drought stress in white clover with different resistance by influencing carbohydrate metabolism and dehydrins synthesis. - Plos ONE 10: e0120708, 2015a.

Li, Z., Peng, Y., Huang, B.: Alteration of transcripts of stressprotective genes and transcriptional factors by $\gamma$-aminobutyric acid (GABA) associated with improved heat and drought tolerance in creeping bentgrass (Agrostis stolonifera). - Int. J. mol. Sci. 19: 1623, 2018.

Li, Z., Peng, D., Zhang, X., Peng, Y., Chen, M., Ma, X., Huang, L., Yan, Y.: $\mathrm{Na}^{+}$induces the tolerance to water stress in white clover associated with osmotic adjustment and aquaporinsmediated water transport and balance in root and leaf. Environ. exp. Bot. 144: 11-24, $2017 \mathrm{~b}$.

Li, Z., Yu, J., Peng, Y., Huang, B.: Metabolic pathways regulated by abscisic acid, salicylic acid and $\gamma$-aminobutyric acid in association with improved drought tolerance in creeping bentgrass (Agrostis stolonifera). - Physiol. Plant. 159: 42-58, $2017 \mathrm{a}$.

Li, Z., Zhang, Y., Zhang, X., Peng, Y., Merewitz, E., Ma, X., Huang, L., Yan, Y.: The alterations of endogenous polyamines and phytohormones induced by exogenous application of spermidine regulate antioxidant metabolism, metallothionein and relevant genes conferring drought tolerance in white clover. - Environ. exp. Bot. 124: 22-38, 2016.

Li, Z., Zhou, H., Peng, Y., Zhang, X., Ma, X., Huang, L., Yan, Y.: Exogenously applied spermidine improves drought tolerance in creeping bentgrass associated with changes in antioxidant defense, endogenous polyamines and phytohormones. - Plant Growth Regul. 76: 71-82, 2015b.

Ma, L., Wang, Y., Liu, W., Liu, Z.: Overexpression of an alfalfa GDP-mannose 3, 5-epimerase gene enhances acid, drought and salt tolerance in transgenic Arabidopsis by increasing ascorbate accumulation. - Biotechnol. Lett. 36: 2331-2341, 2014.

Ma, Q., Yue, L.J., Zhang, J.L., Wu, G.Q., Bao, A.K., Wang, S.M.: Sodium chloride improves photosynthesis and water status in the succulent xerophyte Zygophyllum xanthoxylum. - Tree Physiol. 32: 4-13, 2012.

Mckersie, B.D., Chen, Y., Beus, M., De, Bowley, S.R., Bowler, C., Inzé, D., D'Halluin, K., Botterman, J.: Superoxide dismutase enhances tolerance of freezing stress in transgenic alfalfa (Medicago sativa L.). - Plant Physiol. 103: 1155-1163, 1993.

Nakano, Y., Asada, K.: Hydrogen peroxide is scavenged by ascorbate-specific peroxidase in spinach chloroplasts. - Plant Cell Physiol. 22: 867-880, 1981.
Rosenvasser, S., Mayak, S., Friedman, H.: Increase in reactive oxygen species (ROS) and in senescence-associated gene transcript $(S A G)$ levels during dark-induced senescence of Pelargonium cuttings, and the effect of gibberellic acid. Plant Sci. 170: 873-879, 2006.

Soares, C., De Sousa, A., Pinto, A., Azenha, M., Teixeira, J., Azevedo, R.A., Fidalgo, F.: Effect of 24-epibrassinolide on ROS content, antioxidant system, lipid peroxidation and $\mathrm{Ni}$ uptake in Solanum nigrum L. under Ni stress. - Environ. exp. Bot. 122: 115-125, 2016.

Vaseva, I., Akiscan, Y., Demirevska, K., Anders, I., Feller, U.: Drought stress tolerance of red and white clover-comparative analysis of some chaperonins and dehydrins. - Sci. Hort. 130: 653-659, 2011.

Velikova, V., Yordanov, I., Edreva, A.: Oxidative stress and some antioxidant systems in acid rain-treated bean plants: protective role of exogenous polyamines. - Plant Sci. 151: 59-66, 2000.

Verslues, P.E., Sharp, R.E.: Proline accumulation in maize (Zea mays L.) primary roots at low water potentials. II. Metabolic source of increased proline deposition in the elongation zone. - Plant Physiol. 119: 1349-1360, 1999.

Wang, H.S., Yu, C., Zhu, Z.J., Yu, X.C.: Overexpression in tobacco of a tomato GMPase gene improves tolerance to both low and high temperature stress by enhancing antioxidation capacity. - Plant Cell Rep. 30: 1029-1040, 2011.

Xia, X.J., Wang, Y.J., Zhou, Y.H., Tao, Y., Mao, W.H., Shi, K., Asami, T., Chen, Z., Yu, J.Q.: Reactive oxygen species are involved in brassinosteroid-induced stress tolerance in cucumber. - Plant Physiol. 150: 801-814, 2009.

Yancey, P.H., Clark, M.E., Hand, S.C., Bowlus, R.D., Somero, G.N.: Living with water stress: evolution of osmolyte systems. - Science 217: 1214-1222, 1982.

Zhang, J., Li, H., Xu, B., Li, J., Huang, B.: Exogenous melatonin suppresses dark-induced leaf senescence by activating the superoxide dismutase-catalase antioxidant pathway and down-regulating chlorophyll degradation in excised leaves of perennial ryegrass (Lolium perenne L.). - Front. Plant Sci. 7: 1500, 2016.

Zhang, J., Yu, G., Wen, W., Ma, X., Xu, B., Huang, B.: Functional characterization and hormonal regulation of the pheophytinase gene $L p P P H$ controlling leaf senescence in perennial ryegrass. - J. exp. Bot. 67: 935-945, 2015.

Zhao, D., Oosterhuis, D.: Physiological response of growth chamber-grown cotton plants to the plant growth regulator PGR-IV under water-deficit stress. - Environ. exp. Bot. 38: 7-14, 1997.

Zhao, G.Q., Wang, S.M., Ren, J.Z.: Research progress on genetic transformation and ecological adaptability in white clover. Acta ecol. sin. 24: 592-598, 2004.

Zlatev, Z., Lidon, F.C.: An overview on drought induced changes in plant growth, water relations and photosynthesis. - J. Sci. Food Agr. 24: 520-524, 2012. 